\title{
Isı gereksinimine ve çiğlenme sıcaklığına göre ipekböceği yetiştiriciliğinde uygun besleme döneminin ve çatı örtü malzemesinin belirlenmesi
}

\section{Determination of appropriate rearing period and roof covering material for silkworm rearing by heat requirement and dew point temperature}

\author{
Serpil GENÇOĞLAN@, Ayşe BAŞPINAR, Cafer GENÇOĞLAN@ \\ Kahramanmaraş Sütçü İmam Üniversitesi, Ziraat Fakültesi, Biyosistem Mühendisliği Bölümü, 046100, Kahramanmaraş \\ Sorumlu yazar (Corresponding author): S. Gençoğlan, e-posta (e-mail): sgencoglan@ksu.edu.tr \\ Yazar(lar) e-posta (Authore-mail): abaspinar1985@hotmail.com, gencoglan@ksu.edu.tr
}

MAKALE BİLGİSİ

Alınıs tarihi 08 Ekim 2018

Düzeltilme tarihi 06 Kasim 2018

Kabul tarihi 20 Kasım 2018

\section{Anahtar Kelimeler:}

İpekböceği

Çevre koşulları

Weibull yöntemi

Is1 dengesi

\section{ÖZ}

Bu çalışmanın amacı, farklı çatı örtü malzemeli barınakta yetiştirilen ipekböceğinin 1s gereksinimine ve çiğlenme sıcaklığına göre uygun besleme dönemini ve çatı örtü malzemesini belirlemektir. $\mathrm{Bu}$ amaçla Kahramanmaraş ilinde 20000 adet ipekböceği için doğal havalandırmalı ve 2 farklı çatı örtü malzemeli (düz betonarme tavan, yalıtımsız galvanizli sac) barınak planlanmıştır. İlde dut yapraklarının çıkış zamanı belirlendikten sonra bu zamana denk gelecek şekilde ipekböceği yetiştirme dönemi başlangıç tarihleri 27 Nisan ve 1 Mayıs olarak seçilmiştir. $\mathrm{Bu}$ tarihlerden başlayarak 27 günlük ipekböceği yetiştirme döneminin 1S gereksinimi, 1S1 ve nem dengesi yöntemine göre belirlenmiștir. Nisan ve mayıs aylarının 36 yıllık aylık ortalama sıcaklık ve oransal nem değerlerinin \% 80 olma olasılığı sırasıyla $17.2{ }^{\circ} \mathrm{C}$ ve $21.5^{\circ} \mathrm{C}$ ile $\% 63.2$ ve \% 58.7 olarak bulunmuştur. Yapılan 1 sı hesaplamaları sonucunda 1 Mayıs yetiştiriciliğinin 1sı gereksiniminin diğer döneme göre daha düşük olduğu belirlenmiştir. Düz betonarme tavanlı ipekböceği barınağında yetiştiriciliğe 1 Mayıs'ta başlanıldığında 1Sı gereksinimi, 5 larva döneminde sırasıyla 1203.31, 1018.19, 833.06, 647.94 ve $1780.68 \mathrm{~W} \mathrm{~h}^{-1}$, yalıtımsız galvaniz saclı ipekböceği barınağında ise $1718.35,1453.99$, $1189.63,925.27$ ve $1978.78 \mathrm{~W} \mathrm{~h}^{-1}$ olarak bulunmuștur. Düz betonarme tavanlı barınağın 1sı gereksinimi, yalıtımsız galvanizli saçlı barınağınki ile karşılaştırıldığında 1 . ve 4. larva dönemleri arasında \% 29.97, 5. larva döneminde ise \% 10 daha az olduğu belirlenmiştir. Bu sonuçlara göre hem 1sı gereksiniminin düşük olması hem de dut yapraklarının çıkışı göz önüne alındığında besleme dönemi başlangıcı 1 Mayıs, çatı örtü malzemesi olarak da barınağın ısı gereksinimi ve çatı örtü malzemelerinin çiğlenme sıcaklık değerine göre düz betonarme tavanın daha uygun olduğu belirlenmiştir.

\section{ARTICLE INFO}

Received 08 October 2018

Received in revised form 06 November 2018 Accepted 20 November 2018

\section{Keywords:}

Silkworm

Environmental conditions

Weibull method

Heat balance

\section{ABSTRACT}

The aims of this study are to determine the appropriate rearing period and roof covering material according to the heat requirement of the silkworm grown in the house and the temperature of the dew point temperature. A house of 20000 capacity with natural ventilation and 2 different roof system was planned. The starting dates of silkworm rearing season were selected as 27 April and 1 May. Starting from these dates, the heat requirement of the 27-day silkworm rearing period was determined according to the heat and moisture balance method. Monthly average temperature and relative humidity with $80 \%$ probability for April and May were determined as $17.2^{\circ} \mathrm{C}$ and $21.5^{\circ} \mathrm{C}$ with $63.2 \%$ and $58.7 \%$ respectively. When started rearing silkworm on $1^{\text {th }}$ May in the flat reinforced concrete ceiling silkworm house, the heat requirements in the 5 larvae periods were $1203.31,1018.19,833.06,647.94$ and $1780.68 \mathrm{~W} \mathrm{~h}^{-1}$ respectively. In the uninsulated galvanized sheet metal covered silkworm house, breeding stars on $1^{\text {th }}$ May, the heat requirements in the 5 larvae periods were $1718.35,1453.99,1189.63$, 925.27 and $1978.78 \mathrm{~W} \mathrm{~h}^{-1}$ heat respectively. When compared the heat requirement of a flat reinforced concrete ceiling with that of an uninsulated galvanized steel, it was found that the heat requirement of a flat reinforced concrete ceiling was lesser $29.97 \%$ in the $1-4^{\text {th }}$ and $10 \%$ in $5^{\text {th }}$ larval stages. It was determined that rearing period beginning 1 May and flat reinforced concrete roof were more suitable. 


\section{Giriş}

İpekböceği özellikle dut yapraklarında beslenerek koza şeklinde ham ipek üreten evcilleştirilmiş bir böcektir. Ekonomik kazançlarının yanında biyolojik çalı̧̧malarda model organizma olarak yaygın şekilde kullanılmıştır (Nagaraju ve Goldsmith 2002; Rahmathulla 2012; Singh 2012). İpekböceği soğukkanlı bir böcek olduğundan vücut 1Sisını düzenleyemez. İpekböceğinin büyümesi ve gelişmesinde çevre koşulları önemli rol oynar (Pang-Chuan ve Da-Chuang 1992; Singh 2012; Devi ve Karuna 2012). Bu koşulları sağlamak için yetiştiriciliği özel barınaklarda yapılmaktadır. İpekböceği yetiştiriciliğinde kullanılan yapı, yapının yönü, kullanılan malzemeler, yetiştirme sırasında sicaklık ve nemin korunmasinda hayati bir rol oynamaktadır. Barınağın yapısı, barınakta kullanılan materyaller yerel koşullara ve malzemelere göre planlanıp düzenlenmelidir. Ayrıca ipekböceği barınağının yeri bölgesel çevre koşullarına göre seçilmelidir (Pang-Chuan ve Da-Chuang 1992; Himantharaj ve ark. 1994; Devi ve Karuna 2012; Bhaskar ve Anusha 2015).

Hayvan barınaklarının temel bileşenlerinden biri olan çatı; barınağı kar, yağmur, rüzgâr, sıcak ve soğuk gibi dış tesirlere karş1 korumak estetik bir güzellik ve bütünlük kazandırmak amacıyla inşa edilir (Güner ve Yüksel 2001). Çatı sisteminde kullanılan çatı örtü malzemesi, barınağı atmosferik koşullardan korunmalı, 1sı kayıplarını en aza indirerek yakıt tüketimini azaltmalı ve iyi yalıtım özelliklerine sahip olmalıdır (Ergün ve Kürklü 2008). Solar radyasyon çatıya yaz ve kış aylarında doğrudan geldiği için barınak içi isı enerji hesabında ve ısıtma sistemlerinin tasarımında çatı örtülü malzeme tipi ve özellikleri önemli rol oynamaktadır.

İpekböceği tek bir yıl içinde bir veya birden fazla nesil verebilir. Her y1l üretilen nesil sayısına göre univoltine, bivoltine ve multivoltine olarak siniflandırılır (Dingle ve ark. 2005). İpekböceğinin hayat döngüsü 5 larva dönemine ayrilmaktadır. Yumurtadan çıkan larvalar, iklim ve hava koşullarına bağlı olarak süresi değişen larva döneminde, 4 defa deri değiştirmektedir. Her dönem (yaş), yem yeme ve deri değiştirme (uyku) aşaması olarak ikiye ayrılmaktadır (İnal 2000). Bu aşamalar sırası ile yumurta - larva (tırtıl) - krizalit (pupa, koza) ve kelebek dönemleridir. Besleme yönünden önemli olan dönem larva dönemidir. $\mathrm{Bu}$ dönem uygun koşullarda 26-27 gün sürmektedir (Anonim 2015).

İpekböcekleri tabla, kerevet ve yer beslemesi olmak üzere üç yöntemle beslenmektedir. Kerevet beslemesi, ipekböceği yetiştiriciliği için en uygun besleme şeklidir. Ayaklı 3-4 katlı veya tavandan askılı ranza şeklinde düzenlenen besleme yatakları küçük bir alanda daha fazla ipekböceğinin yetiştirilmesine olanak sağlamaktadır (Anonim 2018a).

Türkiye'de ipekböceği yetiştiriciliği ilkbahar ve sonbahar olmak üzere yılda $2 \mathrm{kez}$ yapılabilmekle birlikte ekonomik anlamda daha verimli olduğu için yalnızca ilkbahar beslemesi gerçekleştirilmektedir. Kuluçkalandırılan ipekböcekleri, havaların daha erken ısındığ ayı başında, diğer bölgelerde nisan ayı sonu ile mayıs ayı başında beslemeye alınmaktadır (Anonim 2018a; 2018b).

Dünyada ipekböceği barınaklarının çatı ve duvar malzemesi özelliklerinin koza üretimine etkileri üzerine birçok çalışma bulunmaktadır (Benchmin ve Jolly 1987; Gangawar ve ark. 1993; Bharathi ve Jayaramarah 2009). Ancak çatı örtü malzeme özelliklerinin barınak içi isı enerjisine etkileri hakkında bilgi eksikliği bulunmaktadır. Bu çalışmanın amacı, Kahramanmaraş ilinde farklı çatı örtü malzemeli barınakta yetiştirilen ipekböceğinin 1sı gereksinimine ve çiğlenme sıcaklığına göre uygun besleme dönemini ve çatı örtü malzemesini belirlemektir.

\section{Materyal ve Yöntem}

\subsection{Materyal}

\subsubsection{Barınak materyali}

Bu çalışmada, ipekböceği yetiştiriciliğinde kullanılacak bir barınak 2 farklı çatı örtü malzemesine göre planlanmıştır. Barınak boyutları ve malzeme özellikleri aşağıda verilmiştir.

Barınağın taban alanı, duvar, kapı, pencere alan ve sayıları aynı kalmak koşuluyla sadece çatı örtü malzemesi değiştirilmiştir. Barınak 20000 larva kapasiteli ve doğal havalandırmalıdır. Kahramanmaraş ilinde tarımsal yapı duvarlarında yaygin olarak 40×20×20 cm'lik briket kullanılmaktadır. Ekmekyapar (1997), Pawar ve ark. (2017) ve Anonim (2018a)'de belirtilen öneri ve ilkeler doğrultusunda barınağın eni $4 \mathrm{~m}$, boyu $6 \mathrm{~m}$ ve yüksekliği ise $2.7 \mathrm{~m}$ alınmıştır. Duvar içten $2 \mathrm{~cm}$, diştan $3 \mathrm{~cm}$ kireç harcıyla sıvanmıştır. Barınak içinde $1 \times 2.5 \mathrm{~m}$ boyutunda 4 kat 3 adet kerevet yaprak besleme standı ve 3 standın arasında $1 \mathrm{~m}$ genişliğinde 2 adet antre, pencere alanı olarak barınak taban alanının \% 15'i hesaplanarak 1 x $1.2 \mathrm{~m}$ boyutlarında 3 adet ahşap pencere ve 1.1 x 2.0 m boyutlarında 1 adet ahşap kapı planlanmıştır.

\subsubsection{Kahramanmaraş İlinin İklimi}

İlin denizden ortalama yüksekliği, $800 \mathrm{~m}$ olup $37^{\circ} 36^{\prime} \mathrm{N}$, $36^{\circ} 55^{\prime}$ E enlem ve boylamlarında yer almaktadir. Kahramanmaraş iline ait uzun yıllık (1960-2014) toplam yağıŞ miktarı $728 \mathrm{~mm}$, ortalama oransal nem, sıcaklık ve rüzgâr hızı sirasiyla $\% 58.3,16.8{ }^{\circ} \mathrm{C}$ ve $2.2 \mathrm{~m} \mathrm{~s}^{-1}$ ' dir. İl, yazlar sicak ve kurak, kışlar ılık ve yağışlı geçen Akdeniz iklim kuşağında yer almaktadır. Akdeniz iklimi, ilin 1000 metreye kadar olan kesimlerinde hâkimdir. Yüksekliği 1000 metreyi aşan kısımlarında, kışları soğuk ve kar yağışlı, yazları nispeten serin bir Akdeniz dağ ikliminin etkileri hissedilir (Düzgün 2017).

Kahramanmaraş ilinde, dut yapraklarının çıkışı nisan ayının ilk haftasına denk geldiğinden, yetiştiriciliğin nisan ve mayıs ayları içerisinde yapılacağı varsayılmıştır. Şekil 1'de ilde bulunan meteoroloji istasyonundan 1980-2016 yılları arasındaki nisan ve mayıs aylarının sicaklık ve oransal nem değerleri alınarak hesaplamalarda kullanılmıştır (Anonim 2017).

\subsection{Yöntem}

Çalışmada ipekböceği barınaklarının 1sı-nem dengesi ve yapı iç yüzey sıcaklığı hesaplamaları yapılarak uygun çatı örtü malzemesi ve yetiştirme dönemi belirlenmiştir. Aşağıda ipekböceği barınak içi çevre koşullarının sağlanmasında gerekli olan iklim verileri ve bu hesaplamalarda kullanılan eşitliklerin belirlenmesine ilişkin kullanılan yöntemler açıklanmıştır.

\subsubsection{Uygun slcaklik ve nem değerlerinin belirlenmesi}

Barınaklarda 1sı ve nem dengesi hesaplamalarında dış sıcaklık ve oransal nem değerlerinin uzun yıllar ortalama değerleri yerine, ortalama değerleri oluşturan y1llık ortalama sıcaklık ve oransal nem değerlerinin ortaya çıkma olasılıkları kullanılmıştır. Bunun için Kahramanmaraş iline ilişkin 36 yıllık ortalama iklim verilerinden yararlanılmıştır. Sıcaklık ve oransal nem değerlerinin ortaya çıkma olasılıkları Weibull yöntemi kullanılarak belirlenmiştir (Tülücü 1988). Uzun yıllık iklim 


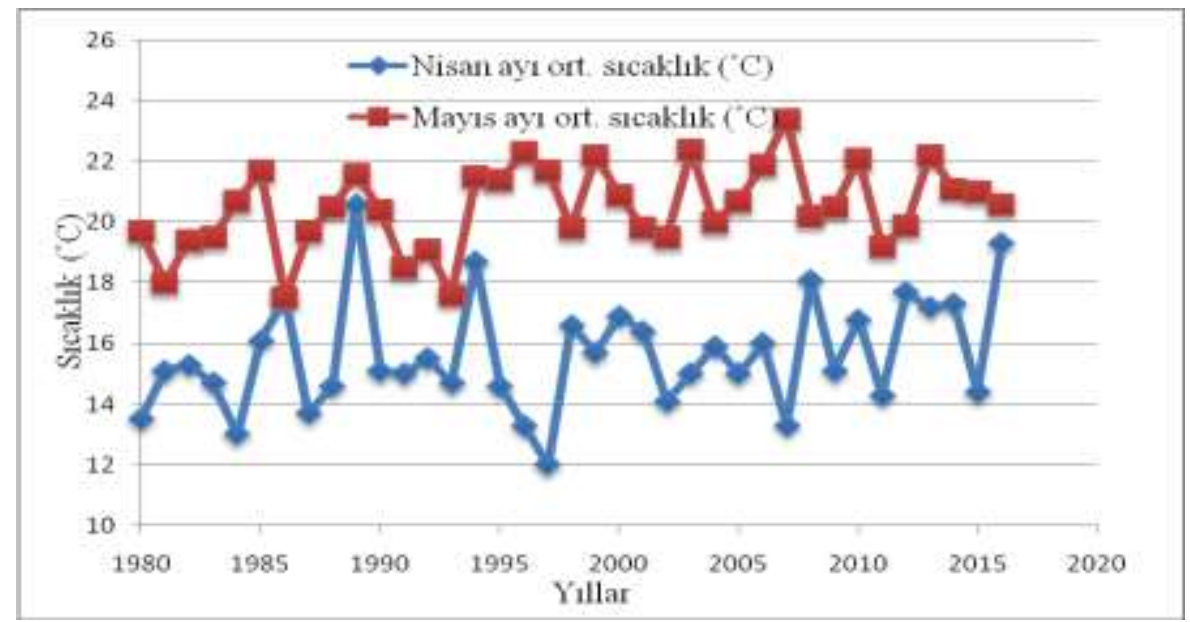

Şekil 1. Uzun yıllık aylık ortalama sıcaklık değerleri (1980-2016).

Figure 1. Monthly average temperature for long term (1980-2016) (Temperature values of April and May rearing months).

verilerinin analizi sonucunda \% 80 olma olasılı̆̆ 1 ile nisanmayıs ayının sıcaklık ve oransal nem değerleri grafikten alınmıştır.

Bu yönteme göre;

$$
\mathrm{F}=(\mathrm{m} / \mathrm{n}+1) * 100
$$

Eşitlikte: $F=$ Yığışımı olasılık (bir değer veya ondan daha büyük değerlerin olma olasıllı̆ı), $\mathrm{m}=$ Büyükten küçüğe göre dizilen değerlerin sıra sayısı, $n=$ Örnek sayısıdır.

\subsubsection{Ist-nem dengesi ile havalandırma hesaplart}

Isı dengesi hesaplamalarında aşağıda verilen eşitlik kullanılmıştır (Lindley ve Whitaker 1996; Öztürk 2003).

$$
\mathrm{Q}_{\mathrm{i}}=\mathrm{q}_{\mathrm{y}}+\mathrm{qh}_{\mathrm{h}}
$$

Eşitlikte; Qi: İpekböceği tarafından ortama verilen hissedilir 1S1 (W), qy: Yapı elemanları (çatı, duvar, pencere, kapı) yoluyla kaybolan toplam isı (W), qh: Havalandırma yoluyla kaybolan is1 (W)'dir.

Yap1 elamanlarından kaybolan 1 sı miktarı (qy) aşağıda verilen eşitlik kullanılarak hesaplanmıştır (Öztürk 2003; Anonim 1994).

$$
\mathrm{q}_{\mathrm{y}}=\Sigma \mathrm{U} \cdot \mathrm{A} \cdot \Delta \mathrm{t}
$$

Eşitlikte; $\Sigma \mathrm{U}$ : Yapı elemanlarının toplam 1sı iletim katsayısı (W $\left.\mathrm{m}^{-2}{ }^{\circ} \mathrm{C}^{-1}\right)$, A: Yap1 elemanının yüzey alanı $\left(\mathrm{m}^{2}\right), \Delta \mathrm{t}$ : ti-td $=$ (ti) iç ve (td) dış ortam sıcaklıkları arasındaki farktır $\left({ }^{\circ} \mathrm{C}\right)$.

Yapı elemanlarının toplam ısı iletim katsayısı (U), aşağıda verilen eşitlik yardımıyla hesaplanmıştır.

$$
U=\frac{1}{\frac{1}{f_{i}}+\sum_{i=1}^{n} \frac{d_{i}}{k_{i}}+\frac{1}{f_{d}}}
$$

Eşitlikte; $f_{i}$ ve $f_{d}$ : İç ve diş yüzey üzerindeki yüzeysel $1 s 1$ iletim katsayıs (kondüktans) ( $\left.\mathrm{W} \quad \mathrm{m}^{-2 \circ} \mathrm{C}^{-1}\right), \mathrm{d}_{\mathrm{i}}(\mathrm{m})$ ve $\mathrm{k}_{\mathrm{i}}$ $\left(\mathrm{W} \mathrm{m}^{-2 \circ} \mathrm{C}^{-1}\right)$ ise sırasıyla içinde $1 \mathrm{~s} 1$ akımı oluşacak yapı elemanının kalınlık ve ısı geçirgenlik katsayı (kondüktivite) değerleridir.
Barınaklardan havalandırma ile kaybolan 1sı miktarı ise aşağıda verilen eşitlikten yararlanılarak belirlenmiştir.

$$
\mathrm{q}_{\mathrm{h}}=0.341 * \mathrm{Q} * \Delta \mathrm{t}
$$

Eşitlikte; qh: Barınaktan havalandırma ile kaybolan 1s1 miktarı (W), 0.341 katsayısı: $1 \mathrm{~m}^{3}$ havanın sıcaklığını $1{ }^{\circ} \mathrm{C}$ yükseltmek için gerekli $1 \mathrm{~s}$ miktarıdır (W $\left.\mathrm{h} \mathrm{m}^{-3}{ }^{\circ} \mathrm{C}^{-1}\right)$. Q: Minimum hava akım miktarı $\left(\mathrm{m}^{3} \mathrm{~h}^{-1}\right), \Delta \mathrm{t}$ : ti-td= (ti) iç ve (td) $\mathrm{d}$ iş ortam sıcaklıkları arasındaki farktır $\left({ }^{\circ} \mathrm{C}\right)$.

Nem kontrolü için yapılan havalandırma, nem dengesi ilkesine dayanır. Rahmathulla (2012)'e göre ipekböceğinin barınak içinde istediği oransal nem değerleri; 1 . ve 2. larva dönemlerinde $\% 85,3$. larva döneminde $\% 80$, 4. ve 5. larva dönemlerinde \% 70'dir. Barınak içinde istenilen oransal nemi bu düzeyde tutabilmek için gereksinim duyulan minimum hava akım miktarı Q $\left(\mathrm{m}^{3} \mathrm{~h}^{-1}\right)$ aşağıdaki eşitlikle hesaplanmıştır (Timmons ve Gates 1987; Albright 1990).

$$
Q=\frac{\sum w_{a}}{q_{i}-q_{d}}
$$

Eşitlikte; $\Sigma$ Wa: Ortama verilen su buharı miktarı $\left(\mathrm{g} \mathrm{h}^{-1}\right)$, qiqd: (iç ve dış) ortam havasının mutlak nem değeri $\left(\mathrm{g} \mathrm{m}^{-3}\right)$ 'dir.

Barınak yüzeyinde oluşan nem yoğunlaşması sık karşılaşılan ve istenmeyen bir durumdur. Yapı elemanları iç yüzey sıcaklıkları hesaplanarak Anonim (2018c)'deki tablodan alınan çiğlenme noktası sıcaklığı ile karşılaştırılmıştır. Eğer yapı elemanları iç yüzey sıcaklığı çiğlenme sıcaklığından küçük ise yap1 elemanı yüzeyinde nem yoğunlaşması kaçınılmazdır. Bu çalışmada yapı elemanlarının iç yüzey sıcaklığı aşağıdaki eşitlik yardımıyla hesaplanmıştır.

$$
t_{s}=t_{i}-\frac{U}{f_{i}}(\Delta t)
$$

Eşitlikte; ts: yapı elemanının iç yüzey sıcaklığı $\left({ }^{\circ} \mathrm{C}\right), \mathrm{f}_{\mathrm{i}}$ : yapı elemanı iç yüzey kondüktansı $\left(\mathrm{W} \mathrm{m}^{-2 \circ} \mathrm{C}^{-1}\right)$. $\mathrm{U}$ : yap1 elemanlarının toplam 1 sı iletim katsayıs1 $\left(\mathrm{W} \mathrm{m}^{-2 \circ} \mathrm{C}^{-1}\right)$. 


\subsection{3. İpekböceği barınă̆ındaki yapı elemanlarının projelenmesi}

Bu çalışmada, ipekböceği barınak çatısı için düz betonarme tavan (DBT) ve yalıtımsız galvanizli sac (YGS) olmak üzere iki farklı çatı örtü malzemesi seçilmiştir. İpekböceği besleme barınağının boyutları ve malzeme özellikleri aşağıda verilmiştir.

DBT'da çatı örtü malzemesi düz betonarme tavandır. Kapı, pencere ve düz betonarme tavana ilişkin toplam 1s1 iletim katsayıları Şahin ve Ünal (2005)'den alınarak sırasıyla 3.49, 2.56, $3.07 \mathrm{~W} \mathrm{~m}^{-2 \circ} \mathrm{C}^{-1}$ dir. Duvar is iletim katsay1s1 Lindley ve Whitaker (1996); Öztürk (2003)'e göre $1.96 \mathrm{~W} \mathrm{~m}^{-2 \circ} \mathrm{C}^{-1}$ olarak hesaplanmıştır (Çizelge 1).

YGS'da çatı örtü malzemesi yalıtımsız galvanizli sac, çatı açısı Ekmekyapar (1997)'e göre $18^{\circ}$ ve beşik çatılı olarak planlanmıştır. Yalıtımsız galvanizli sac çatı örtü malzemesi kalınlığı $0.5 \mathrm{~mm}$ ve 1sı geçirgenlik katsayısı (k) değeri $179 \mathrm{kcal}$ $\mathrm{m}^{-2}{ }^{\circ} \mathrm{C}^{-1}$ olarak Öztürk (2003)'den alınarak hesaplanmıştır.

\subsection{4. İpekböceği ile ilgili projeleme kriterleri}

İpekböceğinin larva süreleri ise 1. larva döneminde yem yeme ve uyku süresi dahil 4 gün, 2. larvada 3 gün, 3. larvada 4 gün, 4. larvada 6 gün, 5. larva döneminde ise 9-10 gün ve toplam larva süresini ise 26-27 gün olduğu belirtilmiştir (İnal 2000). Larva süreleri için genel 1S1 dengesi hesapları Öztürk (2003)'ün verdiği eşitliklerle yapılmıştır. Hesaplamalarda ipekböceği barınağında sicaklık ve oransal nem değerleri her larva dönemi için Rahmathulla (2012)'nin önerdiği değerler kullanılmıştır. İpekböceğinin 1 . ve 2 . larva dönemlerinde barınak içi oransal nem değerleri $\% 85$, 3. larva döneminde $\% 80,4$. ve 5 . larva dönemlerinde $\% 70$ olarak alınmıștır.
Bir kutuda 20000 adet ipekböceği yumurtası bulunmakta olup bunların 18000 'inden larva alınabilmektedir. Besleme döneminde ölenler ve küne ile atılanlar çıkarıldığında 1 kutudan yaklaşık 16000 larva gelişebilmektedir (Başkaya 2013; Anonim 2018d).

İpekböcekleri soğukkanlı canlılar olduğundan, ortama 1S1 ve nem vermediği kabul edilmiştir (Wu ve Hou 1993; Kıraş 2010; Anonim 2018b). Bu nedenle beslemenin ilk haftalarında barınakların elektrikli isiticilar ya da sobalar tarafindan 1sitılması gerekmektedir (Gülseren ve Sipahioğlu 1992; Anonim 2018b). İpekböcekleri sadece 5. larva döneminde koza örmeden önce her 100 larva ortama $40 \mathrm{ml}$ idrar yaparak ortama nem verdiği göz önüne alınarak, 16000 larva için yaklaşık 6400 gr (idrarın özgül ağırlığı $1 \mathrm{~g} \mathrm{~m}^{-3}$ ) olarak belirlenmiştir (İnal 2000).

Yapılan hesaplamalarda kullanılan larva dönem ve süreleri, ipekböceklerinin ortama verdiği su buharı miktarları, ipekböceklerinin barınakta istediği iç ve dış sıcaklık, oransal nem değerleri, iç ve diş mutlak nem değerleri Çizelge 2'de verilmiştir.

\section{Bulgular ve Tartışma}

Kahramanmaraş ilinin uzun yıllık iklim verilerinin analizi sonucunda nisan ve mayıs aylarının aylik ortalama sicaklık ve oransal nem değerlerinin \% 80 olma olasıllığ sirasıyla $17.2^{\circ} \mathrm{C}$ ve $21.5^{\circ} \mathrm{C}, \% 63.2$ ve $\% 58.7$ olarak belirlenmiştir. İlde dut yapraklarının çıkmaya başlaması iklim durumuna göre nisan ayının ilk haftasıdır. Buna göre beslemeye başlama zamanı olarak 27 Nisan ile 1 Mayıs tarihleri seçilmiştir.

Çizelge 1. Planlanan ipekböceği yetiştirme barınağının yapı malzeme bilgileri.

Table 1. Construction material informations of the designed silkworm rearing house.

\begin{tabular}{|c|c|c|c|}
\hline Yapı elemanı & Kullanılan yapı malzemeleri & $\begin{array}{l}\text { Yapı elemanlarının 1sı iletim kat sayısı } \\
(\mathrm{U})\left(\mathrm{W} \mathrm{m}{ }^{-2}{ }^{\circ} \mathrm{C}^{-1}\right)\end{array}$ & $\begin{array}{c}\text { Yapı elemanları alanları } \\
\left(\mathrm{m}^{2}\right)\end{array}$ \\
\hline DBT & Düz betonarme tavan (beton $10 \mathrm{~cm}$ ) & 3.07 & 24.00 \\
\hline YGS & Yalıtımsız galvanizli sac, $18^{\circ}$ 'lik açılı beşik çatı & 6.06 & 25.24 \\
\hline Duvar & $\begin{array}{c}\text { 40x20x20 cm'lik briket (içi } 2 \mathrm{~cm} \text { ve dişı } 3 \mathrm{~cm} \text { kireç } \\
\text { harçla sıvalı) }\end{array}$ & 1.96 & 48.20 \\
\hline Kap1 & 1 adet ahşap $(1.1 \mathrm{~m} * 2 \mathrm{~m})$ boyutunda kapı & 3.49 & 2.20 \\
\hline Pencere & $\begin{array}{c}3 \text { adet ahşap çerçeveli pencere } \\
(1 \mathrm{~m} * 1.2 \mathrm{~m}) \text { boyutlarında }\end{array}$ & 2.56 & 3.60 \\
\hline
\end{tabular}

Çizelge 2. Barınak içi çevre koşullarının sağlanmasında kullanılan iklim verileri.

Table 2. Climate data used in providing optimal environment conditions of rearing house.

\begin{tabular}{|c|c|c|c|c|c|c|c|c|}
\hline \multirow[b]{2}{*}{$\begin{array}{c}\text { Larva } \\
\text { Dönemleri }\end{array}$} & \multirow{2}{*}{$\begin{array}{c}\text { Larva süreleri } \\
\text { (yem+deri değiştirme) } \\
\text { (gün) }\end{array}$} & \multirow{2}{*}{$\begin{array}{l}\text { Su buharı üretimi } \\
\left(\mathrm{ml} 100 \operatorname{larva}^{-1}\right)\end{array}$} & \multicolumn{3}{|c|}{ Sicaklık $\left({ }^{\circ} \mathrm{C}\right)$} & \multirow[b]{2}{*}{ İç (qi) } & \multicolumn{2}{|c|}{ Mutlak nem $\left(\mathrm{g} \mathrm{m}^{-3}\right)$} \\
\hline & & & İç (ti) & Diş (td) & Fark (ti-td) & & Diş (qd) & Fark (qi-qd) \\
\hline \multicolumn{9}{|c|}{ Beslemeye 27 Nisan'da başlandığında kullanılan kriterler } \\
\hline 1. & 4 & 0 & 28 & 17.2 & 10.8 & 23.25 & 9.33 & 13.92 \\
\hline 2. & 3 & 0 & 27 & 21.5 & 5.5 & 22.01 & 11.14 & 10.87 \\
\hline 3. & 4 & 0 & 26 & 21.5 & 4.5 & 19.54 & 11.14 & 8.40 \\
\hline 4. & 6 & 0 & 25 & 21.5 & 3.5 & 16.08 & 11.14 & 4.94 \\
\hline 5. & $9-10$ & 40 & 24 & 21.5 & 2.5 & 15.28 & 11.14 & 4.14 \\
\hline \multicolumn{9}{|c|}{ Beslemeye 1 Mayıs'da başlandığında kullanılan kriterler } \\
\hline 1. & 4 & 0 & 28 & 21.5 & 6.5 & 23.25 & 11.14 & 12.11 \\
\hline 2. & 3 & 0 & 27 & 21.5 & 5.5 & 22.01 & 11.14 & 10.87 \\
\hline 3. & 4 & 0 & 26 & 21.5 & 4.5 & 19.54 & 11.14 & 8.40 \\
\hline 4. & 6 & 0 & 25 & 21.5 & 3.5 & 16.08 & 11.14 & 4.94 \\
\hline 5. & $9-10$ & 40 & 24 & 21.5 & 2.5 & 15.28 & 11.14 & 4.14 \\
\hline
\end{tabular}


Beslemeye 27 Nisan'da başlanırsa DBT çatı örtüsünde ipekböceklerinin 5 larva döneminin 1s1 gereksinimi sirasıyla 1999.35, 1018.19, 833.06, 647.94, 1780.68 $\mathrm{W} \mathrm{h}^{-1}$; 1 Mayıs'ta beslemeye başlandığında 1sı gereksinimi ise 1203.31, 1018.19, 833.06, 647.94, $1780.68 \mathrm{~W} \mathrm{~h}^{-1}$ bulunmuştur. Beslemeye 27 Nisan'da başlanması durumunda 1. larva döneminde 1 Mayıs beslemesine göre \% 66.15 daha fazla 1 s1 gereksinimi olduğu belirlenmiştir. Bulunan 1s1 gereksinim değerleri Gençoğlan ve Başpınar (2016)'nın çatı örtü malzemesi düz betonarme tavan olan ipekböceği barınağının aynı besleme dönemlerindeki 1S1 gereksinim değerlerine benzerlik göstermektedir.

YGS çatı örtüsünde beslemeye 27 Nisan'da başlandığında 5 larva dönemindeki 1S1 gereksinimi sırasıyla 2855.11, 1453.99, 1189.63, 925.27, 1978.78 $\mathrm{W} \mathrm{h}^{-1}, 1$ Mayıstaki beslemede 1s1 gereksinimi ise $1718.35,1453.99,1189.63,925.27,1978.78$ $\mathrm{W} \mathrm{h}^{-1}$ olarak bulunmuştur. Beslemeye 27 Nisan'da başlanması durumunda 1. larva döneminde 1 Mayıs beslemesine göre $\% 66.15$ daha fazla 1sı gereksinimi olduğu belirlenmiştir.

İpekböceğinin 1s1 gereksinim hesaplamasında 27 Nisan ile 1 Mayıs beslemesi karşılaştırıldığında sadece ilk haftanın 1sı değerinin farklı olduğu gözlenmiştir. Bunun nedeni beslemenin ilk dört günü nisan ayının içinde olmasındandır. Hesaplamalarda nisan ayının sicaklık ve nem değerlerinin kullanılmasındandır. Isı gereksiniminin 5. larva döneminde yükselmesi ise ipekböceklerinin bu dönemde ortama idrar vermesinden kaynaklanmaktadır. Eğer idrar vermediği kabul edilseydi 5. larva döneminde DBT çat1 örtüsünün 1S1 gereksinimi $462.81 \mathrm{~W} \mathrm{~h}^{-1}$, YGS çatı örtüsünün 1s1 gereksinimi ise $690.91 \mathrm{~W} \mathrm{~h}^{-1}$ olacaktır.

Beslemeye 1 Mayıs'ta başlandığında DBT çatı örtüsünün 1S1 gereksinimi YGS çatı örtüsüne göre 1. ile 4. larva dönemlerinde
$\%$ 29.97, 5. larva döneminde ise \% 10 daha az olduğu belirlenmiştir (Şekil 2).

Beslemeye 27 Nisan'da başlandığında DBT çatı örtüsünde 1. larva döneminde; kapı, pencere, duvar ve çatısında, yetiştiriciliğe 1 Mayıs'ta başlanıldığında 1. larva döneminde kapı, duvar ve çatıda çiğlenme görülmektedir (Çizelge 3).

YGS çatı örtüsünde beslemeye 27 Nisan'da başlandığında 1. larva döneminde; kap1, pencere, duvar ve çatıda, 2 ve 3 . larva döneminde; çatıda, 1 Mayıs beslemesinde ise 1. larva döneminde; kapı, duvar ve çatıda, 2 ve 3. larva döneminde; çatıda çiğlenme görülmektedir. Her iki çatı örtü malzemesi ve besleme döneminde 1. larva döneminde bütün yapı elemanlarında çiğlenme görülmesinin sebebi larvaların ilk dönemde yüksek sicaklık ve oransal nem istemelerinden kaynaklanmaktadır.

$\mathrm{Bu}$ çalışmada, Kahramanmaraş ilinde 27 gün süren ipekböceği beslemesinde 5 larva döneminde barınağın 1sitılması gerektiği bulunmuştur. Isı gereksiniminin en düşük 1 Mayıs besleme döneminde olduğu ve çiğlenme sıcaklığına göre çatı örtü malzemesi olarak da düz betonarme tavanın uygun olduğu belirlenmiştir.

İlk üç larva döneminde ipekböceklerinin yüksek oransal nem gereksiniminden dolayı yapı elemanları (kapı, pencere, duvar, tavan, çatı) yüzeyinde çiğlenme görülmektedir. DBT çatı örtüsünde 1 Mayıs beslemesinde sadece 1. larva döneminde kapı, duvar ve çatıda çiğlenme görülmektedir. Çiğlenme olmaması için ya yapı elemanlarında yalıtım malzemesi kullanılmalı ya da barınak içi iyi bir şekilde havalandırılmalıdır.

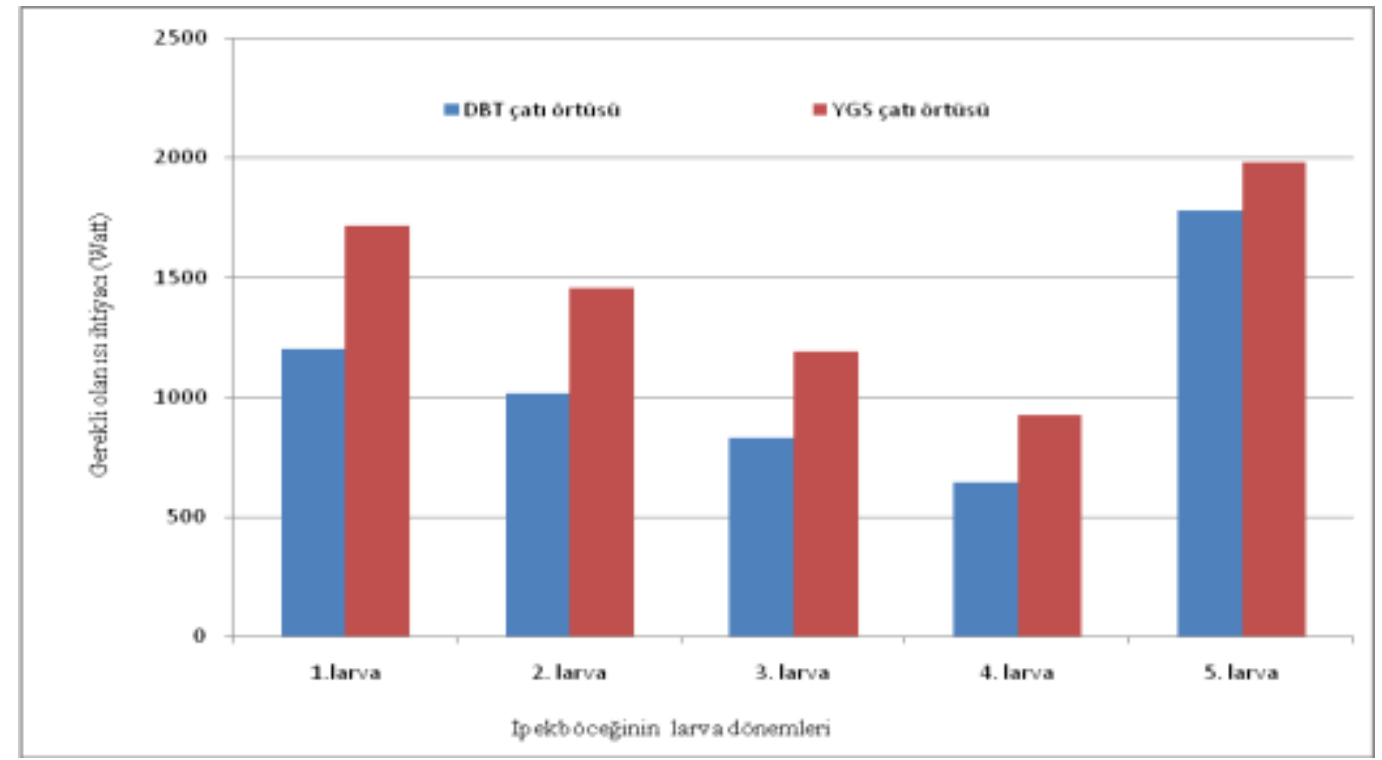

Şekil 2. Barınak çatı özelliklerine göre ipekböceğin 1 Mayıs beslemesindeki ısı gereksinimi.

Figure 2. Silkworm heat requirement for 1 May rearing periods according to the house roof features. 
Çizelge 3. Barınakta kullanılan yapı elemanlarının iç yüzey ve çiğlenme noktası sıcaklıkları.

Table 3. Internal surface and dew point temperatures of structure elements used in the rearing house.

\begin{tabular}{|c|c|c|c|c|c|c|c|c|c|c|}
\hline \multirow{2}{*}{$\begin{array}{c}\text { Larva } \\
\text { Dönemi }\end{array}$} & \multirow{2}{*}{$\begin{array}{c}\text { Larva süreleri } \\
\text { (yem+deri değiştirme) } \\
\text { (gün) }\end{array}$} & \multirow{2}{*}{$\begin{array}{c}\text { Oransal nem }(\%) \\
\text { İç } \\
\text { ortam }\end{array}$} & \multicolumn{2}{|c|}{ Sicaklık $\left({ }^{\circ} \mathrm{C}\right)$} & \multicolumn{5}{|c|}{ Yapı elemanları iç yüzey sıcaklığı $\left({ }^{\circ} \mathrm{C}\right)$} & \multirow{2}{*}{$\begin{array}{c}\text { Çiğlenme noktası } \\
\text { sıcaklığı }\end{array}$} \\
\hline & & & $\begin{array}{c}\text { Diş } \\
\text { ortam }\end{array}$ & $\begin{array}{c}\text { İç } \\
\text { ortam }\end{array}$ & $\begin{array}{c}\text { Diş } \\
\text { ortam }\end{array}$ & Kap1 & Pencere & Duvar & Tavan & \\
\hline \multicolumn{11}{|c|}{ Düz betonarme tavanlı çatı örtüsü } \\
\hline \multicolumn{11}{|c|}{ Beslemeye 27 Nisan'da başlandığında kullanılan kriterler } \\
\hline 1. & 4 & 85 & 63.2 & 28 & 17.2 & 22.62 & 24.05 & 23.26 & 23.26 & 25.50 \\
\hline 2. & 3 & 85 & 58.7 & 27 & 21.5 & 24.26 & 24.99 & 24.59 & 24.59 & 24.00 \\
\hline 3. & 4 & 80 & 58.7 & 26 & 21.5 & 23.76 & 24.36 & 24.03 & 24.03 & 22.00 \\
\hline 4. & 6 & 80 & 58.7 & 25 & 21.5 & 23.26 & 23.72 & 23.46 & 23.46 & 19.00 \\
\hline 5. & $9-10$ & 70 & 58.7 & 24 & 21.5 & 22.18 & 23.09 & 22.90 & 22.90 & 18.00 \\
\hline \multicolumn{11}{|c|}{ Beslemeye 1 Mayıs'da başlandığında kullanılan kriterler } \\
\hline 1. & 4 & 85 & 58.7 & 28 & 21.5 & 24.76 & 25.62 & 25.15 & 25.15 & 25.50 \\
\hline 2. & 3 & 85 & 58.7 & 27 & 21.5 & 24.26 & 24.99 & 24.59 & 24.59 & 24.00 \\
\hline 3. & 4 & 80 & 58.7 & 26 & 21.5 & 23.76 & 24.36 & 24.03 & 24.03 & 22.00 \\
\hline 4. & 6 & 80 & 58.7 & 25 & 21.5 & 23.26 & 23.72 & 23.46 & 23.46 & 19.00 \\
\hline 5. & $9-10$ & 70 & 58.7 & 24 & 21.5 & 22.75 & 23.09 & 22.90 & 22.90 & 18.00 \\
\hline \multicolumn{11}{|c|}{ Yalıtımsız galvanizli sac çatı örtüsü } \\
\hline \multicolumn{11}{|c|}{ Beslemeye 27 Nisan'da başlandığında kullanılan kriterler } \\
\hline 1. & 4 & 85 & 63.2 & 28 & 17.2 & 22.62 & 24.05 & 23.26 & 18.65 & 25.50 \\
\hline 2. & 3 & 85 & 58.7 & 27 & 21.5 & 24.26 & 24.99 & 24.59 & 22.24 & 24.00 \\
\hline 3. & 4 & 80 & 58.7 & 26 & 21.5 & 23.76 & 24.36 & 24.03 & 22.10 & 22.00 \\
\hline 4. & 6 & 80 & 58.7 & 25 & 21.5 & 23.26 & 23.72 & 23.46 & 21.97 & 19.00 \\
\hline 5. & $9-10$ & 70 & 58.7 & 24 & 21.5 & 22.18 & 23.09 & 22.90 & 21.84 & 18.00 \\
\hline \multicolumn{11}{|c|}{ Beslemeye 1 Mayıs'da başlandığında kullanılan kriterler } \\
\hline 1. & 4 & 85 & 58.7 & 28 & 21.5 & 24.76 & 25.62 & 25.15 & 22.37 & 25.50 \\
\hline 2. & 3 & 85 & 58.7 & 27 & 21.5 & 24.26 & 24.99 & 24.59 & 22.24 & 24.00 \\
\hline 3. & 4 & 80 & 58.7 & 26 & 21.5 & 23.76 & 24.36 & 24.03 & 22.10 & 22.00 \\
\hline 4. & 6 & 80 & 58.7 & 25 & 21.5 & 23.26 & 23.72 & 23.46 & 21.97 & 19.00 \\
\hline 5. & $9-10$ & 70 & 58.7 & 24 & 21.5 & 22.75 & 23.09 & 22.90 & 21.84 & 18.00 \\
\hline
\end{tabular}

\section{Kaynaklar}

Albright LD (1990) Natural ventilation. Steady-state energy and mass balances environment control for animals and plants. pp. 143-320.

Anonim (1994) ASAE Agricultural standarts, ASAE, 41 ST Edition. Michigan-USA.

Anonim (2015) İpekböcekçiliği ve yetiştiriciliği. URL http://www.kozabirlik.com.tr/ipekböcekçiliği/ipekbocekciligiveyeti stiriciligi. Erişim 20 Mart 2015.

Anonim (2017) Kahramanmaraş ilinin iklim verileri. Kahramanmaraş İli Meteoroloji Müdürlüğü.

Anonim (2018a) 2017 Yılı ipekböceği raporu. Kozabirlik Bursa Tarım Dergisi. URL http://www. SS.Bursa Koza Tarım Satış Kooperatifleri Birliği. Erişim 10 Temmuz 2018.

Anonim (2018b) İpekböcekçiliği. Ünvan değişikliği sınavı, tekniker (İpek Böcekçiliği) ders notu. T.C. Gıda, Tarım ve Hayvancılık Bakanlığ1, Personel Genel Müdürlügüü. URL http://www.tarim.gov.tr/PERGEM/Link/124/Unvan-DegisikligiDesr-Notlari ipekböcekciligi.pdf. Erişim 11 Temmuz 2018.

Anonim (2018c) Dew Point Temperature at Atmospheric Pressure in Degrees Celsius.

http://www.nationalcompressedair.com/dat/files/600.pdf. Erişim 19 Eylül 2018.

Anonim (2018d) İpekböceği yetiştiriciliği basın açıklaması. URL http://www.belekomahaber.com/ipekbocekciligi-yetistiriciligibasin-aciklamasi/. Erişim 11 Temmuz 2018.

Başkaya Z (2013) Gelişimi ve dağılışı bakımından türkiye ipekböcekçiliğinde Bilecik ilinin yeri, sorunları ve çözüm önerileri. Doğu Coğrafya Dergisi Cilt: 18, Sayı: 30, s. 257-286.

Benchmin KV, Jolly MS (1987) "The Principles of Silkworm Rearing”, In Proc. Natn. Semin. Seric. Mahalingam, S., (Ed.,) University of Madras, pp. 63-108.
Bharathi VP, Jayaramaiah M (2009) Impact of rearing houses on cocoon productivity in mulberry silkworm. Bull. Ind. Acad. Seri. 13(1): 49-53.

Bhaskar RN, Anusha HG (2015) Role of micro environment in the rearing house a boon for quality cocoon production in Eastern Dryzone of Karnataka. Proceedings of the International Conference on Science Connecting Healty and Society Held at Colombo, Sri Lanka, 28-29 November 2015.

Devi R, Karuna T (2012) Silkworming rearing technology for the course of sericulture. URL

http://bie.telangana.gov.in/files/SilkwormRearing Technology.pdf. Erişim 05 Ekim 2018.

Dingle JG, Hassan E, Gupta M, George D, Anota L, Begum H (2005) Silk production in Australia. A report for the Rural Industries Research and Development Corporation. pp. 105.

Düzgün M (2017) Programlanabilir lojik kontrol (PLC) tabanlı sulama otomasyon sistemi ile sulanan Comice armut (Pyrus Communis 1.) çeşidi su-verim ilişkisinin ve bitki su stres indeksinin (CWSI) belirlenmesi. Yüksek Lisans Tezi, Kahramanmaraş Sütçü İmam Üniversitesi, Fen Bilimleri Enstitüsü, Kahramanmaraş. s. 59.

Ekmekyapar T (1997) Tarımsal inşaat. Atatürk Üniversitesi Ziraat Fakültesi Yayınları No: 151. s. 197.

Ergün A, Kürklü G (2008) Çatı tasarımı ve uygulamasında detay hataları, sonuçları ve düzeltme çalışmaları. 4. Ulusal Çatı \& Cephe Kaplamalarında Çağdaş Malzeme ve Teknolojiler" Sempozyumu, İTÜ Mimarlık Fakültesi Taşkışla- İstanbul 13-14 Ekim 2008.

Gangawar SK, Somasundram P, Nataraja N (1993) Silkworm rearing performance under different rearing houses in Tamil Nadu. Indian Silk 32(7): 37- 38.

Gençoğlan S, Başpınar A (2016) Determination of the silkworm (Bombyxmori L.) Heat requirements in rearing room of village house for optimal environmental conditions. Pakistan Journal of Zoology Vol: 48(2): 557-561. 
Gülseren C, Sipahioğlu O (1992) İpekböcekçiliği. Tarım ve Köy işleri Bakanlığı Teşkilatlanma ve Destekleme Genel Müdürlüğü Yaygın Çiftçi Eğitimi Projesi. s. 60.

Güner MS, Yüksel A (2001) Yapı Bilgisi Kitabı. Aktif yayınevi, İstanbul, s. 444.

Himantharaj MT, Kamble CK, Rajan RK, Data RK (1994) Silkworm rearing house construction: An ideal approach. Indian Silk, 33(4): 19-22.

İnal Ş ( 2000) İpekböceği yetiştiriciliği. URL http://veteriner.selcuk.edu.tr/veteriner/not_soru/ipek.htm Erişim 17 Şubat 2014.

Kıraş SN (2010) Bursa'da ipek üretiminin yöresel konut mimarisinde mekan biçimlenmesi ve mekan organizasyonları üzerindeki etkilerinin incelenmesi. (Yüksek Lisans Tezi). Yıldız Teknik Üniversitesi, Fen Bilimleri Enstitüsü.

Lindley JA, Whitaker JH (1996) Agricultural Building and Structures. ASAE, USA.

Nagaraju J, Goldsmith MR (2002) Silkworm genomics-progress and prospects. Curr. Sci. 83: 415-425.

Öztürk T (2003) Tarımsal yapılar. 19 Mayıs Üniversitesi Ziraat Fakültesi. Ders Kitap No: 49. Samsun.

Pang-Chuan W, Da-Chuang C (1992) Silkworm rearing. Food and Agriculture Organization of the United Nations, Roma, pp. 81.
Pawar A, Supekar Y, Shinde M, Pandhare S, Nagare PS (2017) Optimization in comfort conditions of silkworm rearing house. International Journal of General Science and Engineering Research (IJGSER), ISSN 2455-510X, Vol 3(2): 122-125.

Rahmathulla VK (2012) Management of climatic factors for successful silkworm (Bombyxmori L.) Cropand Higher Silk Production. Psyche: 2012: 1-12.

Şahin A, Ünal HB (2005) Yapı malzeme bilgisi. Ege Üniversitesi Yayınları. Ziraat Fakültesi Yayın No: 568, s. 316.

Singh A (2012) Environmental influence on larval duration in silkworm bivoltine hybrid NB4D2XSH6, Bombyx Mori L. Bionano Frontier, 5(2): 253-255.

Timmons MB, Gates RS (1987) Relative humidity as a ventilation control parameter in broiler housing. Transactions of the ASAE. Vol: 30(4): 1111-1115.

Tülücü K (1988) Uygulamalı Hidroloji. Çukurova Üniversitesi, No: 76, s. 36-51, Adana.

Wu DJ, Hou RF (1993) Relationship between thermo tolerance and heat-stable esterase in the silkworm, Bombyxmori. Appl. Entolomol. Zool. 28(3): 371-377. 